\title{
To compare the effects of multiple sessions of Hyperbaric Oxygen Therapy in neurological improvement in head injury patients: A prospective randomized trial
}

\author{
Amlendu Yadav, Mridula Pawar, Rakesh Garg, Neerja Banerjee
}

\begin{abstract}
Introduction: Hyperbaric oxygen therapy (HBOT) is used to improve functional outcome following brain injuries. Different number of sessions of HBOT have been reported but the frequency of HBOT sessions in head injured patients has not been standardized. We planned this prospective randomized study with an aim to compare the neurological effects of 10,20 and 30 sessions of HBOT in the head injured patients. Materials and Methods: After review board approval, this study was conducted in 60 head injury patients with Glasgow Coma Scale (GCS) score $\leq 9$. All patients were resuscitated, stabilized and received neurological care according to institutional protocol. Patients were randomly allotted to-Group HIO (n-20)-which received 10 sittings of HBOT, Group H2O (n-20)-which received 20 sittings of HBOT, Group H30 (n-30)-which received 30 sittings of HBOT. GCS score was recorded after every 10 sittings and at 30 days from initiation of HBOT. Improvement Global rating and Glasgow outcome scale (GOS) were recorded after 30 days. Results: The maximum improvement in GCS scores was seen in group H30. The difference in the average improvement global rating scale was significant between group $\mathrm{HIO}$ and group $\mathrm{H} 20$, between group $\mathrm{HIO}$ and group $\mathrm{H} 30$ but was comparable between groups $\mathrm{H} 20$ and $\mathrm{H} 30$. The $\mathrm{GOS}$ was better after 30 sessions as compared to 10 sessions. Patients of all groups showed improvement in spasticity but group $\mathrm{H} 30$ showed a maximum improvement. Conclusion: A minimum of 30 HBOT sessions should be considered in head injury patients to show improvement with HBOT. Progressive improvement in GCS scores, GOS, spasticity, mood swings was better seen with increased number of HBOT sessions.
\end{abstract}

Key words: Glasgow Coma Scale score, head injury, hyperbaric oxygen therapy, neurological improvement

\section{INTRODUCTION}

The general management of traumatic brain injury usually aims at maintenance of oxygenation and

\begin{tabular}{|l|l|}
\hline \multicolumn{2}{|c|}{ Access this article online } \\
\hline Quick Response Code: & Website: \\
\hline & www.jnaccjournal.org \\
\cline { 2 - 2 } & \\
\hline & \\
\hline
\end{tabular}

perfusion. ${ }^{[1]}$ This further necessitates the supportive therapy in addition to surgical intervention. Hyperbaric oxygen therapy (HBOT) is the modality for management where ischaemia or related factors affect the tissue viability. In such cases hyperbaric oxygen delivery reduces infection and cell death and thus maintains tissue viability and increases the chances of tissue healing. ${ }^{[2]}$ HBOT is a mode of treatment in which the patient is entirely enclosed in a pressure chamber and breathes $100 \%$ oxygen at a pressure greater than 1 atmosphere absolute (ATA). Among the various indications apart from hyperbaric therapy like decompression sickness, embolism, infections, etc., it has been found to have

Department of Anaesthesiology and Intensive Care, Postgraduate Institute of Medical Education and Research, Dr. Ram Manohar Lohia Hospital, New Delhi, India

Address for correspondence:

Dr. Rakesh Garg, Department of Anaesthesiology and Intensive Care, Postgraduate Institute of Medical Education and Research, Dr. Ram Manohar Lohia Hospital, New Delhi - 110 011, India. E-mail: drrgarg@hotmail.com 
a positive role in head injury patients. ${ }^{[3]}$ Hyperbaric oxygen is presently being used in an attempt to improve functional outcome following a multitude of brain injuries such as stroke, anoxic brain injury, and traumatic brain injury. ${ }^{[4]}$ Various authors have used different number of sessions of HBOT with variable results but the frequency of HBOT sessions in head injured patients has not been standardized. ${ }^{[5,6]}$ It seems that the clinical benefit is dependent upon the dose of HBOT. ${ }^{[7]}$

Therefore, the aim of the present study was to evaluate the optimal number of HBOT sessions required for head injured patient. Thus, we planned this prospective randomized study with an aim to compare the neurological effects of 10, 20 and 30 sessions of HBOT in the head injured patients.

\section{MATERIALS AND METHODS}

This prospective randomized study was conducted after getting approval from institutional research and ethical committee approval. Sixty patients of age 1-80 years with head injury were included in the study. Patients with history of head injury and Glasgow Coma Scale (GCS) score $\leq 9$ were included in the study. Patients with history of pneumothorax, chronic obstructive pulmonary disease (COPD), absent brain stem reflexes, seizures and otosclerosis were excluded from the study. A written informed consent was taken from next of kin or care provider. All patients were resuscitated, stabilized and received neurological care according to institutional protocol. Patients were randomly allotted using computer generated randomization number to either of the three groups and number concealed in opaque closed envelope:

- Group H10 (n-20) - received 10 sittings of HBOT

- Group H20 (n-20) - received 20 sittings of HBOT

- Group H30 (n-20) - received 30 sitting of HBOT.

Baseline computerized tomography (CT) scan was recorded and categorized (I - no visible pathology seen on CT scan; II - Cisterns are present with shift $0-5 \mathrm{~mm}$, no high or mixed density lesion $>25 \mathrm{~mL}$, may include bone fragments and foreign bodies; III - cisterns compressed or absent, shift of 0-5 mm, no high or mixed density lesion $>25 \mathrm{~mL}$; IV - shift $>5 \mathrm{~mm}$, high or mixed density lesion $>25 \mathrm{~mL}){ }^{[3]}$ The patients in all groups were administered HBOT in a monoplace chamber at 1.5 ATA for a duration of 60 minutes for 6 days a week. Electrocardiogram, non-invasive automated blood pressure, respiratory rate and pulse oximeter monitoring was done during the therapy. GCS score ${ }^{[8]}$ was the primary outcome variable and was recorded by an independent investigator (anesthesiologist) after every 10 sittings and at 30 days from initiation of HBOT in all groups. Improvement in Global rating was done by an independent investigator (anesthesiologist) on a scale of $0-100$ at 30 days in all groups. ${ }^{[9,10]}$ Glasgow outcome scale (GOS $)^{[11]}$ was recorded in all patients after 30 days in all the groups. The muscle spasticity was measured and graded as per Modified Ashworth Scale. ${ }^{[12]}$ The improvement in the muscle spasticity grade of 1 or more was considered improvement and was noted. The requirement of tracheostomy and its removal was noted. The day at which Ryle's tube was removed was noted. All groups received the intensive standard of care for brain injury consistent with institutional protocol. Surgical intervention was done whenever required. All observations were noted by an independent observer who was unaware of the number of sittings of the HBOT.

\section{Statistical analysis}

The improvement in GCS score of $>4$ among the groups was assumed to be clinically significant, and based on this assumption with a power of $80 \%$ and $\alpha$ of -0.05 , a total of 60 patients (randomized in three groups of 20 each) were recruited for the study. The statistical software, SPSS 13 (SPSS Inc., Chicago, IL) was used for data analysis. The data are presented in terms of descriptive statistics for categorical variables and descriptive variables for continuous variables (range, mean, median, standard deviation). The significance across the three groups was done through Kruskal-Wallis test if the distribution of data followed skewed distribution. The parametric data are compared using one-way ANOVA and repeated measures ANOVA. Statistical significance was defined as $P<0.05$.

\section{RESULTS}

Sixty patients were randomized into three groups of 20 each. The three groups were comparable with respect to demographic profile, mode of injury and baseline parameters [Table 1]. The neurosurgical intervention was comparable in the three groups $(P>0.05)$. Baseline median GCS scores were comparable in the three groups [Table 2]. The GCS scores improved with the initiation of HBOT. There was insignificant improvement in GCS scores in group $\mathrm{H} 10$ between the end of $10 \mathrm{HBOT}$ sittings and at $30^{\text {th }}$ day $(P=0.56)$. Also, insignificant improvement in scores of group $\mathrm{H} 20$ between the end of 20 sittings and at $30^{\text {th }}$ day $(P=0.781)$ was observed.

The difference in the average improvement in global rating scale was significant between group H10 and group $\mathrm{H} 20$, between group $\mathrm{H} 10$ and group $\mathrm{H} 30$ but was comparable between groups $\mathrm{H} 20$ and H30 [Table 3]. The GOS was better after 20 and 30 sessions of HBOT as compared to 10 sessions of HBOT.

Patients of all groups showed improvement in spasticity but group H30 showed the maximum improvement [Table 3]. Similarly lesser number of patients showed mood swings in group $\mathrm{H} 30$ and 
Table 1: Demographic profile and baseline parameters

\begin{tabular}{lcccc}
\hline Parameters & $\begin{array}{c}\text { Group } \\
\text { H10 } \\
(\boldsymbol{n}-\mathbf{2 0})\end{array}$ & $\begin{array}{c}\text { Group } \\
\text { H20 } \\
(\boldsymbol{n} \text {-20) }\end{array}$ & $\begin{array}{c}\text { Group } \\
\text { H30 } \\
(\boldsymbol{n} \text {-20) }\end{array}$ & $\boldsymbol{P}$ \\
\hline $\begin{array}{l}\text { Age, Median } \\
\text { (range) (years) }\end{array}$ & $22(1-55)$ & $27(6-63)$ & $24(16-67)$ & 0.8 \\
$\begin{array}{l}\text { Sex } \\
\text { (Male:Female) }(n)\end{array}$ & $4: 16$ & $8: 12$ & $7: 13$ & 0.43 \\
$\begin{array}{l}\text { Preoperative CT } \\
\text { category } \\
\text { (I: II: III: IV) (n) }\end{array}$ & $6: 6: 4: 4$ & $1: 9: 6: 4$ & $2: 8: 5: 5$ & 0.08 \\
$\begin{array}{l}\text { Delay in HBOT } \\
\text { from day of injury } \\
\text { (median) (days) }\end{array}$ & 14 & 13 & 14 & 0.9 \\
$\begin{array}{l}\text { Patients on } \\
\text { anticonvulsants }(n)\end{array}$ & 15 & 16 & 14 & 0.9 \\
\hline
\end{tabular}

$\mathrm{CT}$ = Computed tomographic scan, HBOT = Hyperbaric oxygen therapy

Table 2: GCS (E, V, M) scores at various stages of HBOT (baseline, 10, 20, 30 days of HBOT)

\begin{tabular}{lccc}
\hline & $\begin{array}{c}\text { Group } \\
\text { H10 } \\
(\boldsymbol{n}-\mathbf{2 0})\end{array}$ & $\begin{array}{c}\text { Group } \\
\text { H20 } \\
(\boldsymbol{n} \text {-20) }\end{array}$ & $\begin{array}{c}\text { Group } \\
\text { H30 } \\
(\boldsymbol{n} \text {-20) }\end{array}$ \\
\hline Baseline & $6(1,1,4)$ & $6(1,1,4)$ & $6(1,1,3)$ \\
At 10 days/sittings & $11(3,3,5)$ & $11(3,3,5)$ & $10(3,2,4)$ \\
At 20 days/sittings & $12(3,3,6)$ & $13(4,4,6)$ & $12(4,3,5)$ \\
At 30 days/sittings & $12(3,3,6)$ & $14(4,4,6)$ & $13(4,3,6)$ \\
$P$ value & 0.001 & 0.001 & 0.001 \\
\hline
\end{tabular}

HBOT = Hyperbaric oxygen therapy, GCS = Glasgow coma scale

Table 3: Improvement in study parameters after 30 days of starting HBOT

\begin{tabular}{lcccc}
\hline Parameters & $\begin{array}{c}\text { Group } \\
\text { H10 } \\
(\boldsymbol{n}-\mathbf{2 0})\end{array}$ & $\begin{array}{c}\text { Group } \\
\text { H20 } \\
(\boldsymbol{n}-\mathbf{2 0})\end{array}$ & $\begin{array}{c}\text { Group } \\
\text { H30 } \\
(\boldsymbol{n} \text {-20) }\end{array}$ & $\boldsymbol{P}$ \\
\hline $\begin{array}{l}\text { Patients with } \\
\text { improvement in } \\
\text { spasticity, } n(\%)\end{array}$ & $13(65)$ & $18(90)$ & $20(100)$ & 0.01 \\
$\begin{array}{l}\text { Average im- } \\
\text { provement in } \\
\text { global rating }\end{array}$ & 73.7 & 88.3 & 88 & 0.02 \\
$\begin{array}{l}\text { GOS } \\
\text { (I: II: III: IV: V) }(n)\end{array}$ & $10: 0: 1: 6: 3$ & $17: 1: 0: 2: 0$ & $15: 2: 1: 2: 0$ & 0.01 \\
$\begin{array}{l}\text { Patients with } \\
\text { mood swings, } \\
n(\%)\end{array}$ & $18(90)$ & $13(65)$ & $2(10)$ & 0.01 \\
\hline
\end{tabular}

HBOT = Hyperbaric oxygen therapy, GOS = Glasgow outcome scale

group $\mathrm{H} 20$ as compared to group H10. Four patients were tracheostomized in group H10, 3 patients in group $\mathrm{H} 20$ and 5 patients in group $\mathrm{H} 30$. At the end of 30 days of HBOT, $25 \%$ patients were decannulated in group $\mathrm{H} 10$ as compared to $66 \%$ in group $\mathrm{H} 20$ and $40 \%$ in group H30. The Ryle's tube was removed in 53\% of patients in group $\mathrm{H} 10$ as compared to $90.5 \%$ and $85.7 \%$ in group $\mathrm{H} 20$ and group H30, respectively at the end of 30 days of starting of HBOT.

None of the patients had any episode of seizures or pulmonary complications in any of the groups.

\section{DISCUSSION}

We observed from our study that administration of HBOT in patients with head injury improves the GCS score, Improvement Global Rating, GOS, and spasticity. The improvement increased with the number of sittings. The mood swings were also improved with increased sessions of HBOT. Also, patients were decannulated and Ryle's tube removed early on increasing the HBOT sittings in patients with head injury.

HBOT is an adjunctive therapy that has been proposed to improve outcome in acute brain injury. ${ }^{[13]}$ Mechanisms by which hyperbaric oxygen improves sequelae following brain injury are speculative. Its use in traumatic brain injury (TBI) is based on the theory that damaged cells are "Idling neurons" in the ischemic penumbra (the border between healthy and damaged brain tissue), which may have the potential to recover ${ }^{[13]}$ Improving oxygen availability to these cells may stimulate the cells to function normally, reactivating them metabolically or electrically, resulting ultimately in angiogenesis and other signs of healing. Hyperbaric oxygen up-regulates growth factor receptor sites on human endothelium and can stimulate healing in hypoxic wounds. It is conceivable that hyperbaric oxygen exerts similar effects within damaged neuronal tissue but this information is lacking. Stem cells are present in the adult brain and there is speculation that hyperbaric oxygen may stimulate these stem cells to generate new neurons, but once again, this information is speculative. ${ }^{[6,13]}$

In a recent Cochrane review of seven studies including 571 patients (285 received HBOT and 286 were controls), it was concluded that HBOT as compared to control causes significant improvement in GOS (RR 0.74, 95\% CI 0.61 to $0.88, P=0.001){ }^{[6]}$ The overall mortality was less in group receiving HBOT as compared to controls (RR $0.69,95 \%$ CI 0.54 to $0.88, P=0.003$ ). The improvement in GCS for patients treated with HBOT as compared to controls was reported in this Cochrane review (95\% CI 1.84 to 3.52, $P<0.0001$ ). Mao et al. explored the benefits of HBOT in head injury in 60 patients (30 received HBOT and 30 were controls). ${ }^{[14]}$ The study groups received HBOT once a day with 4-70 days. They observed that GCS score increased significantly at 20, 30 and 90 days of treatment $(P<0.05)$. Also, the GOS score in HBOT group improved significantly as compared to control group $(P=0.01)$. Our results are comparable with Lin et al. who reported overall improvement of the GCS score. ${ }^{[4]}$ 
However, these patients received more than 100 HBOT sessions as compared to 10-30 sessions in our study. Early initiation of therapy arrested the chain of events, which led to the improvement in GCS score with less number of HBOT sessions in our study. There was insignificant improvement in scores of group $\mathrm{H} 20$ between the end of 20 sittings and at $30^{\text {th }}$ day $(P=0.781)$. Also, insignificant improvement in GCS scores was noted in group H10 between the end of 10 HBOT sessions and at $30^{\text {th }}$ day $(P=0.56)$. Once HBOT sessions were stopped, the improvement became static. This may be because a certain minimum number of sessions are required to maintain the continuous improvement in the GCS scores. This cumulative effect of HBOT in clinical improvement was documented by Zarabeth et al. ${ }^{[15]}$ However, further studies are required to know the exact number of sessions required to have the improvement in neurological outcome after HBOT in head inured patients. GOS improved after hyperbaric therapy in patients with traumatic brain injury. ${ }^{[4]}$ Similar improvement was seen in our study when GOS was compared. It was also found the GOS improved further with increase in HBOT from 10 to 30 sessions. The in-hospital mortality rate was decreased with increased number of HBOT sessions in our study. The improvement in spasticity and mood swings increased with number of HBOT sessions.

There are also concerns regarding potential adverse effects of the therapy, including damage to the ears, sinuses and lungs from the effects of pressure, temporary worsening of short-sightedness, claustrophobia and oxygen poisoning. ${ }^{[16]}$ The reported incidence for significant pulmonary impairment is $13 \%$ where patient received HBOT as compared to none in controls. ${ }^{[6]}$ The occurrence of seizures and haemotympanum was reported in 2 patient each out of 84 patients who received HBOT as compared to none in control group $(P=0.3) \cdot{ }^{[17]} \mathrm{We}$ excluded patients with any ear or pulmonary pathologies for the study purpose. Following these exclusions, none of our patients had such complication. No neurological complications like seizures (though some of our patients were on anticonvulsants) occurred in our patients.

Our study is limited by the fact that long-term outcome of HBOT in head injury patients was not studied. Also, patients were not followed up for neuropsychiatric complications. We also included all types of head injury rather than a specific group of head injury to study the effects of multiple sessions of HBOT. The impact of further increase in HBOT sessions and ceiling effect of the number of HBOT sessions needs to be evaluated further.

\section{CONCLUSION}

To conclude, increasing the HBOT sessions from 10 to 30 have favourable outcome in patients of head injury.
Progressive improvement in GCS scores, GOS, spasticity, mood swings was seen with increased number of HBOT sessions from 10 to 30 .

\section{REFERENCES}

1. Algattas $\mathrm{H}$, Huang JH. Traumatic brain injury pathophysiology and treatments: Early, intermediate and late phases post injury. Int J Mol Sci 2014;15:309-41.

2. Huang L, Obenaus A. Hyperbaric oxygen therapy for traumatic brain injury. Med Gas Res 2011;1:21.

3. Gill AL, Bell CN. Hyperbaric oxygen: Its uses, mechansim of action and outcomes. QJM 2004;97:385-95.

4. Lin JW, Tsai JT, Lee LM, Lin CM, Hung CC, Hung KS, et al. Effect of hyperbaric oxygen on patients with traumatic brain injury. Acta Neurochir Suppl 2008;101:145-9.

5. Chorr V, Canini F, De Rudnicki S, Dahmani S, Gressens P, Constantin P. Hyperbaric oxygen therapy and inert gases in cerbral ischaemia and traumatic brain injury. Ann Fr Anesth Reanim 2013;32:863-71.

6. Bennett MH, Trytko B, Jonker B. Hyperbaric oxygen therapy for the adjunctive treatment of traumatic brain injury. Cochrane Database Syst Rev 2012;12:CD004609.

7. Rockswold SB, Rockswold GL, Defillo A. Hyperbaric oxygen in traumatic brain injury. Neurol Res 2007;29:162-72.

8. Teasdale G, Jennett B. Assessment of coma and impaired consciousness-A practical scale. Lancet 1974;2:81-4.

9. Tsevat J, Dawson NV, Matchar DB. Assessing quality of life and preferences in the seriously ill using utility theory. J Clin Epidemiol 1990;43:73-7.

10. deGuise E, leBlanc J, Feyz M, Meyer K, Duplantie J, Thomas H, et al. Long-term outcome after severe traumatic brain injury: The McGill interdisciplinary prospective study. J Head Trauma Rehabil 2008;23:294-303.

11. Lingsma HF, Roozenbeek B, Steyernerg EW, Murray GD, Maas AI. Early prognosis in traumatic brain injury: From prophecies to predictions. Lancet Neurol 2010;9:543-54.

12. Bohannon RW, Smith MB. Interrater reliability of a modified Ashworth Scale of muscle spasticity. Phys Ther 1986;67:206-7.

13. McDonaugh M, Helfand M, Carson S, Russman BS. Hyperbaric oxygen therapy for traumatic brain injury: A systematic review of the evidence. Arch Phys Med Rehabil 2004;85:1198-204.

14. Mao JH, Sun ZS, Xiang Y. Observation of curative effects of hyperbaric oxygen for treatment on severe craniocerebral injury. J Clin Neurol 2010;23:386-68.

15. Golden ZL, Neubauer R, Golden CJ, Greene L, Marsh J, Mleko A. Improvement in cerebral metabolism in chronic brain injury after hyperbaric oxygen therapy. Int J Neurosci 2002;112:119-31.

16. Plafki C, Peters $P$, Almeling $M$, Welslau W, Busch R. Complications and side effects of hyperbaric oxygen therapy. Aviat Space Environ Med 2000;71:119-24.

17. Rockswold SB, Rockswold GL, Zaun DA, Zhang X, Cerra CE, Bergman TA, et al. A prospective, randomized clinical trial to compare the effect of hyperbaric to normobaric hyperoxia on cerebral metabolism, intracranial pressure, and oxygen toxicity in severe traumatic brain injury. J Neurosurg 2010;112:1080-94.

How to cite this article: Yadav A, Pawar M, Garg R, Banerjee N. To compare the effects of multiple sessions of Hyperbaric Oxygen Therapy in neurological improvement in head injury patients: A prospective randomized trial. J Neuroanaesthesiol Crit Care 2015;2:110-3.

Source of Support: Nil, Conflict of Interest: None declared. 